\title{
artigo
}

\section{A saúde coletiva na articulação da educação e empoderamento de mulheres Kalunga: uma revisão sistemática}

\author{
Collective health in the articulation of education and empowerment of Kalunga women: a systematic review \\ La salud colectiva en la articulación de la educación y el empoderamiento de las mujeres Kalunga: una revisión sistemática
}

\begin{abstract}
RESUMO
Objetivo: Sistematizar, mapear e reconhecer as produções por meio de aspectos metodológicos e evidências identificando temáticas e abordagens dominantes e emergentes. Método: realizou-se uma busca no Portal de Periódicos da Capes, com os descritores "quilombos e Kalunga, educação, saúde e empoderamento", com recorte temporal de 2001 a 2019, elegendo no total 41 artigos para leitura. Resultados: apontaram crescimento significativo de produções acadêmicas elaboradas sobre as comunidades quilombolas - Kalunga, porém a quantidade de achados é pouco expressiva, frente ao povoado, em especial, as mulheres. Conclusão: notou-se que nas diferentes abordagens dadas pelos trabalhos analisados, que as comunidades remanescentes dos quilombolas têm empreendido lutas pelos direitos à educação, saúde, cidadania, igualdade e territorialidade. Houve um avanço significativo na autonomia das mulheres Kalunga, porém ainda é necessário que o sistema político intervenha com maior atenção a essa população, pois as discussões acerca do processo de empoderamento das mulheres Kalunga ainda são incipientes. DESCRITORES: Educação; Empoderamento; Escravização; Acesso a serviços de saúde.
\end{abstract}

\section{ABSTRACT}

Objective: To systematize, map and recognize productions through methodological aspects and evidence identifying dominant and emerging themes and approaches. Method: a search was carried out on the Capes Journal Portal, with the descriptors "quilombos and Kalunga, education, health and empowerment", with a time frame from 2001 to 2019, electing a total of 41 articles for reading. Results: they pointed out a significant growth of academic productions elaborated on the quilombola communities - Kalunga, however the amount of findings is not very significant, compared to the village, especially women. Conclusion: it was noted that in the different approaches given by the analyzed studies, that the remaining quilombola communities have been fighting for the rights to education, health, citizenship, equality and territoriality. There has been a significant advance in the autonomy of Kalunga women, but it is still necessary for the political system to intervene with greater attention to this population, as discussions about the process of empowering Kalunga women are still incipient.

DESCRIPTORS: Education; Empowerment; Enslavement; Access to health services.

\section{RESUMEN}

Objetivo: Sistematizar, mapear y reconocer producciones a través de aspectos metodológicos y evidencias identificando temas y enfoques dominantes y emergentes. Método: se realizó una búsqueda en el Portal de Revistas Capes, con los descriptores "quilombos y Kalunga, educación, salud y empoderamiento", con un marco temporal de 2001 a 2019, eligiendo un total de 41 artículos para lectura. Resultados: señalaron un crecimiento significativo de las producciones académicas elaboradas sobre las comunidades quilombolas - Kalunga, sin embargo la cantidad de hallazgos no es muy significativa, en comparación con la aldea, especialmente mujeres. Conclusión: se observó que en los diferentes enfoques dados por los estudios analizados, las comunidades quilombolas restantes han venido luchando por los derechos a la educación, la salud, la ciudadanía, la igualdad y la territorialidad. Ha habido un avance significativo en la autonomía de las mujeres Kalunga, pero aún es necesario que el sistema político intervenga con mayor atención a esta población, ya que las discusiones sobre el proceso de empoderamiento de las mujeres Kalunga aún son incipientes.

DESCRIPTORES: Educación; Empoderamiento; Esclavitud; Acceso a los servicios de salud.

RECEBIDO EM: 22/02/2021 APROVADO EM: 03/03/2021 


\title{
Sonilda Aparecida de Fátima Silva
}

Pedagoga, graduada pela Faculdade de Filosofia do Vale de São Patrício (1994), Psicopedagoga (1996), Administradora Escolar (1998) e Mestre em Gestão do Patrimônio Cultural (PUC -2006). Doutoranda em Educação na PUC-GO.

ORCID: 0000-0001-7760-5065

\section{Lúcia Helena Rincón Afonso}

Graduada em História. Doutora em Educação pela Universidade Estadual Paulista Júlio de Mesquita Filho (UNESP 2002). Professora adjunto da Pontifícia Universidade Católica de Goiás.

ORCID: 0000-0003-3130-8246

\author{
Vannúzia Leal Andrade Peres \\ Psicóloga. Doutora em Psicologia; Pós Doutora em Educação (Universidade de Brasília). \\ ORCID: 0000-0002-7323-0654
}

\section{José Xavier Rodovalho}

Pedagogo, Administrador de Empresa e Sociólogo, Mestre em Educação pela UEX - Universidade de Extremadura-ES, revalidação Pontifícia Universidade Católica de Goiás -GO, Doutorando em Psicologia pela PUC-GO.

ORCID: 0000-0002-0432-2571

\section{Alda Nazaré Santos do Nascimento}

Pedagoga, Psicóloga. Especialista em Gestão Escolar, Psicopedagoga, Neuropedagoga, Psicodramatista em Formação. Mestra em Educação e Doutoranda em psicologia pela Pontifícia Universidade Católica de Goiás, Goiânia, Brasil. Professora da Rede Municipal de Goiânia.

ORCID: 0000-0003-2292-6034

\section{INTRODUÇÃO}

$\mathbf{P}$ ensar no papel social desempenhado pelas mulheres na sociedade brasileira, mais especificamente, sob a ótica do empoderamento feminino, das lutas e resistências da mulheres das comunidades Kalunga é importante para a compreensão da sociedade brasileira em sua diversidade, principalmente quando leva-se em consideração que na cultura dos remanescentes dos quilombos, as comunidades foram construídas sob a égide do machismo. ${ }^{1}$

O povo Kalunga é uma comunidade de negros, originalmente formada por descendentes de escravos que fugiram do cativeiro e organizaram um quilombo. A história oficial dos quilombos de Goiás pode ter começado na década de 1720 , na região norte e nordeste de Goiás, onde se formaram vários quilombos entre os séculos XVIII e XIX. Em sua maior parte eram escravos fugitivos das minas de ouro, das redondezas. ${ }^{2}$

Nesta premissa o povo quilombo Kalunga surgiu em decorrência da extração do ouro em Cavalcante, como também das minas existentes em Morro do Chapéu, atualmente Monte Alegre de
Goiás (Goiás) e Arraias (Tocantins). Esses três municípios são próximos e, na época da mineração, eram considerados rota do ouro no nordeste goiano. ${ }^{3,4}$

Neste direcionamento de formações das comunidades vale ressaltar a importância do direito à saúde de todos os povos ancorados no Sistema Único de Saúde (SUS), onde a saúde passou a ser entendida como "um estado de completo bem-estar físico, mental e social e não somente a ausência de afecções ou enfermidades". Sendo assim, um dos direitos fundamentais de todo o ser humano sem distinção de 'raça', religião, ideologia política e condição econômica e social”. 5,6

Contudo, o pleno acesso aos serviços públicos de saúde e de qualidade, para toda a população brasileira, ainda é uma conquista longe de se efetivar na prática. Isto, pois, se torna mais evidente ao se enfocar populaçôes historicamente marginalizadas quanto ao acesso a políticas públicas, como é o caso das comunidades quilombolas, sendo a visão de vulnerabilidade social, usualmente, referida nos quilombos em relação à saúde e à doença. ${ }^{7}$

Neste sentido, o viver das mulheres Kalunga está aquém da integração das prá- ticas prioritárias em educação básica e em saúde dentro de uma política pública individual e coletiva. Nesse espaço de atuação, a equipe de saúde defronta-se com obstáculos de natureza político-institucionais e organizacionais, pois, geograficamente, encontra-se o maior desafio, disponibilizar a educação e a saúde pública à comunidade Quilombola-Kalunga. ${ }^{8}$ Contudo, as marcas do momento histórico e político vividos em movimentos sociais de resistências, nas relações de poder e na busca por sobrevivência das mulheres Kalunga, descendentes dos quilombolas, podem ser identificadas como processo cultural vivido dentro do próprio quilombo. ${ }^{9}$

Deste modo, torna-se evidente o surgimento de inquietações e o desejo de pesquisar sobre as histórias de resistências dessas mulheres em diversos âmbitos de resiliência para compreender as formas organizativas sociais de resistências, as relações de poder, de sobrevivência e o empoderamento social/cultural das mulheres Kalunga da região nordeste do Estado de Goiás.

Dessa forma, buscou-se responder às seguintes questóes: como a literatura tem articulados a saúde coletiva, a educação 


\section{artigo}

Fátima Silva, S.A.; Afonso, L.H.R.; Peres, V.L.A.; Rodovalho, J.X.; Nascimento, A.N.S.;

A saúde coletiva na articulação da educação e empoderamento de mulheres Kalunga: uma revisão sistemática

básica e o empoderamento de mulheres Kalunga remanescentes dos quilombolas? Quais são as principais evidências e aspectos metodológicos empregadas em tais estudos?

O estudo objetivou-se em sistematizar, mapear e reconhecer as produções por meio de aspectos metodológicos e evidências identificando temáticas e abordagens dominantes e emergentes.

\section{MÉTODO}

O presente estudo seguiu as recomendações do Preferred Reporting Items for Systematic Reviews and Meta-Analyses (PRISMA), no qual visa orientar a divulgação de revisões sistemáticas da literatura (RSL) e meta-análises na área da saúde. Contudo, este estudo trata-se de uma RSL sem meta-análise. ${ }^{10}$

$\mathrm{O}$ procedimento metodológico pautou-se na revisão da literatura de artigos localizados nos Períodicos da Capes em versões ampliadas utilizando as bases Springer, Elsevier, Science Direct Jounals, Scientific Electronic Library Online - SciELO e Open Acess Journal. Para a busca eletrônica nas bases de dados selecionadas, foram utilizados os descritores nos idiomas português e inglês sendo esses: quilombos e Kalunga, educação e empoderamento na saúde - "quilombos and Kalunga, education, health and empowerment", com o recorte temporal de 2001 a 2019 , os procedimentos de buscas foram realizados entre os meses de janeiro a maio do ano de 2019.

Os critérios de inclusão constituíram-se na seleção de artigos empíricos, oriundos de revisão por pares, disponíveis e completos, publicados nos periódicos da Capes e, artigos que contemplassem no assunto (mulheres quilombolas e o empoderamento refletido na saúde) de forma associada. Por conseguinte, os critérios de exclusão consistiram em descartar estudos não disponíveis na íntegra, artigos que no tema e/ ou assunto não apresentassem definição completa dos aspectos metodológicos e evidências, artigos repetidos, editoriais e resumos expandidos.

Vale ressaltar que foram realizadas várias inserções e refinamentos para possibilitar, a partir das pesquisas já realizadas, para construir as propostas. Selecionou-se a área das ciências humanas e saúde e obteve-se 488 resultados. A partir desses resultados procedeu-se a uma leitura atenta de cada estudo e por meio da análise dos

Figura 1- Fluxo de informações com diferentes fases da revisão sistemática PRISMA acerca da saúde coletiva na articulação da educação e no empoderamento de mulheres Kalunga remanescentes dos quilombolas (Galvão et al.,2015).

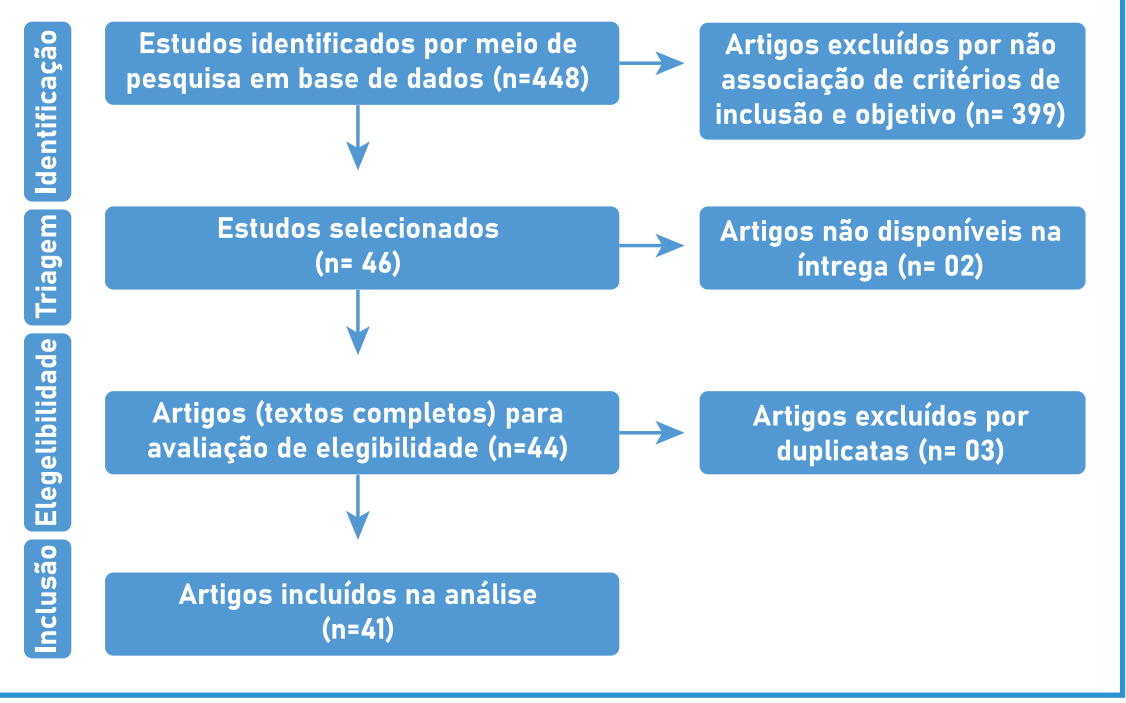

resumos dos trabalhos disponibilizados, percebeu-se que muitos dos trabalhos não se alinhavam ao objetivo da pesquisa e critério de inclusão.

Neste sentido, de acordo com o Figura 1 foram identificados 49 artigos nas bases de dados que considerassem a temática, optando por uma leitura criteriosa dos artigos na íntegra focando-se em artigos que contemplavam o objetivo do estudo.

Sendo assim, foram selecionados 46 artigos que atendiam os critérios de inclusão, na sequência percebeu-se que 02 artigos não estavam disponíveis na íntegra, permanecendo uma elegibilidade de 44 artigos e destes 03 artigos foram excluídos por duplicidade. Na totalidade foram incluídos na revisão sistemática 41 artigos para análise.

As análises dos artigos deu-se por meio dos títulos, resumos e/ou abstracts sendo realizadas por dois juízes separadamente, em julgamento duplo cego e posteriormente, um terceiro juiz realizou a avaliação e análise final. Os 41 artigos finais foram analisados na íntegra e classificados nas seguintes categorias: Título do Artigo, Autor; Periódicos e Data de Publicação.

A Figura 1 apresenta o fluxograma do PRISMA, explicitando os processos de realização da revisão sistemática, com a descrição completa de todas as fases do estudo de acordo com os critérios de inclusão e exclusão elegidos.

\section{RESULTADOS}

No que se refere a tipos de estudo 28 foram mistos - qualitativos e qualitativo, ao que diz respeito ao corte de estudo, 09 eram transversais e 04 longitudinais. A respeito dos países de estudo, todos os artigos foram publicados no Brasil e, a partir de então foi realizada uma análise das pesquisas (41 artigos). Destes, para melhor compreensão e didática foram elegidos na forma de síntese 10 artigos, sendo distribuídos 05 em relação a Identidade e Educação (básica e saúde) e 05 em relação a Territorialidade que trouxeram diferentes aspectos da constituição e da educação em saúde, com o objetivo de apresentar uma 
discussão sobre educação básica e cultural dos quilombolas ocorridas nos achados conforme Quadro 1.

Sendo assim, foi evidenciada uma análise histórico-cultural e uma abordagem em relação a cultura, saúde, identidade e a subjetividade quilombola (mulheres Kalunga), baseando-se no imaginário social construído sobre esses sujeitos trazendo uma análise dos materiais didáticos de Educação Escolar Quilombola (EEQ) da Educação Básica e Saúde ${ }^{11}$, produzidos especificamente por diferentes sistemas de ensino e saúde estaduais no país, confrontando-os com as Diretrizes Curriculares Nacionais $(D C N)^{12}$ e a Política Nacional de Atenção Básica (PNAB). ${ }^{13}$

Em um contexto geral, os resultados revelaram um crescimento significativo de produções acadêmicas elaboradas so- bre as comunidades quilombolas, porém essa quantidade de pesquisa ainda é pouco expressiva, frente à quantidade de quilombos e escolas quilombolas existentes no Brasil, em especial as mulheres. Os temas mais discutidos foram cultura, identidade, territorialidade e saúde, o que tornou possível a categorização em dois eixos: territorialidade quilombola e Educação (básica e em saúde) da cultura quilombola.

Referentes ao primeiro eixo "territorialidade quilombola", as pesquisas tratam da construção da identidade Kalunga, os quais proporcionaram visualizar a trajetória dos remanescente dos quilombolas sendo possível perceber que em pleno século XXI as lutas para a construção da identidade encontram-se vivas, mesmo após a conquista histórica da libertação dos escravos, tais desigualdades incidem sobre a totalidade da vida dessas comunidades. E, em relação ao segundo eixo, vale ressaltar a percepção na literatura investigada referente a desorganização no planejamento e execução in loco de políticas em saúde coletiva a essa população.

Verificou-se que mediante a análise dos trabalhos relacionados às comunidades remanescentes dos quilombolas, torna-se necessário relatar que a utilização do termo "remanescentes de quilombos" é uma forma de tornar essas comunidades negras nomeáveis, classificando-as e admitindo nelas a presença do negro/escravo, com fim de dar a elas visibilidade.

\section{DISCUSSÃO}

Ao analisar as relações entre desigualdades étnico-raciais e as políticas de saúde

\begin{tabular}{|c|c|c|c|}
\hline & TÍTULO DO ARTIGO & AUTOR & PERIÓDICO/DATA \\
\hline \multicolumn{4}{|c|}{ IDENTIDADE E EDUCAÇÃO (BÁSICA E SAÚDE) } \\
\hline 01 & $\begin{array}{l}\text { A constituição de um território identitário pela } \\
\text { garantia dos direitos fundiários: o sítio histórico e } \\
\text { patrimônio Cultural Kalunga }\end{array}$ & Luana Nunes Martins de Lima & Soc.nat. vol.25 set./dez. 2013 \\
\hline 02 & $\begin{array}{l}\text { De gente de cor a quilombolas: desigualdades, } \\
\text { religião e identidade }\end{array}$ & Wilson José Ferreira de Oliveira & Cad.CRH v.26 no.67 Salvador. 2013 \\
\hline 03 & $\begin{array}{l}\text { Os desafios da educação quilombola no Brasil: o } \\
\text { território como contexto e texto }\end{array}$ & Lourdes de Fátima Bezerra Carril & $\begin{array}{c}\text { Rev.Bras.Educ. vol.22 no.69 Rio de } \\
\text { Jan/Abr/jun, } 2017\end{array}$ \\
\hline 04 & $\begin{array}{l}\text { Cultura, identidade e subjetividade quilombola: uma } \\
\text { leitura a partir da psicologia cultural }\end{array}$ & $\begin{array}{l}\text { Marcella Brasil Furtado; Regina } \\
\text { Lúcia Sucupira Pedroza; Cândida } \\
\text { Beatriz Alves }\end{array}$ & $\begin{array}{l}\text { Psicol. Soc. vol. } 26 \text { no.1 BH jan./abr. } \\
\qquad 2014\end{array}$ \\
\hline 05 & $\begin{array}{l}\text { Educação escolar quilombola no Brasil: uma análise } \\
\text { sobre os materiais didáticos produzidos pelos siste- } \\
\text { mas estaduais de ensino. }\end{array}$ & $\begin{array}{l}\text { Elivaldo Serrão Custódio Eugénia da } \\
\text { Luz Silva Foster }\end{array}$ & $\begin{array}{l}\text { Educar revista vol.35 no.74 Curiti- } \\
\text { bamar./abr. } 2019\end{array}$ \\
\hline \multicolumn{4}{|c|}{ TERRITORIALIDADE } \\
\hline 01 & $\begin{array}{l}\text { A constituição de } 1988 \text { e a ressignificação dos qui- } \\
\text { lombos contemporâneos limites e potencialidades }\end{array}$ & $\begin{array}{l}\text { Carlos Eduardo Marques; Lîlian } \\
\text { Gomes }\end{array}$ & $\begin{array}{l}\text { Rev.Ci.Soc. vol.28 no.81 São Paulo } \\
\text { fev. } 2018\end{array}$ \\
\hline 02 & $\begin{array}{l}\text { Os quilombos perante o STF: a emergência de uma } \\
\text { jurisprudência dos direitos étnicos. }\end{array}$ & João Carlos Bemerguy Camerini & $\begin{array}{l}\text { Rev. Direito GV vol.8. no.1 SP jan./ } \\
\text { jun. } 2016\end{array}$ \\
\hline 03 & $\begin{array}{l}\text { Territorialidade e cultura entre os Kalunga: para além } \\
\text { do culturalismo }\end{array}$ & Thais Alves Marinho & Cad.CRH v.30 n.80 Salvador, 2017 \\
\hline 04 & $\begin{array}{l}\text { Panorama atual de proteção do direito à terra das } \\
\text { comunidades quilombolas e desafios futuros }\end{array}$ & $\begin{array}{l}\text { Germana Aguiar Ribeiro do Nasci- } \\
\text { mento et al }\end{array}$ & $\begin{array}{l}\text { Interações.vol.17 no.3 Campo } \\
\text { Grande, } 2016\end{array}$ \\
\hline 05 & $\begin{array}{l}\text { O suor marca a terra: trabalho, direito e território } \\
\text { quilombola na llha do Marajó-Pará }\end{array}$ & Luis Fernando Cardoso e Cardoso & $\begin{array}{l}\text { Amb soc.vol.18n.2 SãoPaulo abr./ } \\
\text { jun.2015 }\end{array}$ \\
\hline
\end{tabular}


e educação na constituição de comunidades de quilombos e as respectivas estratégias de enfrentamento vivenciadas pelos negros na comunidade. ${ }^{14}$ Com isso, verificou-se que o reconhecimento legal dos quilombos no Brasil representa um marco histórico na visibilidade das diferenças étnicas e culturais da sociedade e que o mito da democracia racial escondeu as dores da escravidão, causando lesões nas identidades afrodescendentes ${ }^{15}$.

No presente estudo foi possível registrar a luta e a trajetória do povo Kalunga na conquista do território em Cavalcante, Estado de Goiás, tendo como base de pesquisa a memória de lideranças e de jovens, bem como documentos oficiais e bibliografias já escritas sobre o povo Kalunga. Corroborando com o estudo autores apresentaram as realidades vivenciadas e os direitos adquiridos, enfatizando as contradições entre a legislação e sua efetiva aplicação, principalmente no que se refere ao direito do território e da educação. ${ }^{16}$

Um outro estudo enfatiza que é preciso destacar que a ideologia é destruída pelo enviesamento ideológico da legislação, pois é usada por aqueles que pouco dela precisam, para salvaguardar seus privilégios", ${ }^{17}$ ou seja, a legislação educacional passa a ser estratagema ideológico, mesmo quando volta-se para consolidar a igualdade, incluindo índios, negros, pessoas com necessidades educativas especiais, historicamente excluídas do direito à educação e desconsideradas nas suas diferenças e particularidades. ${ }^{18}$

Confirmando os dados encontrados, estudos enfocam sobre as fragilidades da legislação da educação básica e em saúde, que trazem relatos construídos a partir de experiências vivenciadas em viagem a campo, junto às Comunidades Kalunga nos povoados de Vão de Almas, Vão do Moleque, Engenho e Diadema. ${ }^{19}$

Autores destacam em seus estudo as análises referentes ao direito à educação como expressão de cidadania face à realidade educacional na Comunidade remanescente quilombola Kalunga, considerando os preceitos Constitucionais de 1988, a Lei de Diretrizes e Bases da
Educação Nacional de 1996 e a Emenda Constitucional n. 59/2009.20

No presente estudo foi possível registrar a luta e a trajetória do povo Kalunga na conquista do território em Cavalcante, Estado de Goiás, tendo como base de pesquisa a memória de lideranças e de jovens, bem como documentos oficiais e bibliografias já escritas sobre o povo Kalunga.

Neste sentido, a contextualização do campo empírico trouxe o conhecimento da origem da escola pública naquela comunidade, bem como a luta empreendida pelos moradores para a sua institucionalização e revelou os desafios no tocante à garantia do acesso, permanência e aproveitamento, com qualidade, do alunado na escola ${ }^{21}$.

Portanto a educação em sua complexidade de dimensões é "como uma atividade mediadora no seio da prática social”, ou seja, como meio para emancipação humana, pois é uma prática social, que busca desenvolver na pessoa humana os saberes e fazeres pertinentes para sua formação e emancipação. Percebe-se que as escolas, em sua maioria, atendem às ideias dominantes, mantendo a hegemonia da classe dominante, ou seja, atende às demandas de mercado e não às demandas sociais. ${ }^{22}$

Neste contexto, notou-se o quanto as políticas públicas direcionadas à população afrodescendente, notadamente os quilombolas, foram legitimadas com a Constituição Federal de $1988^{22}$, possibilitando a esse segmento da população maior visibilidade, acesso a bens de consumo e assistência à saúde. Contudo, tais conquistas ainda estão longe de refletir a ruptura da condição de vulnerabilidade historicamente construída. Não obstante, a conquista dos direitos serem recentes, ainda carece de efetivação quanto ao atendimento dos anseios da população Kalunga em ter seus pleitos atendidos, em prol da melhoria nas condições de vida, pois as iniquidades são mais intensas quando comparadas com os demais membros da sociedade. ${ }^{23}$

Por isto, quando se enfoca a educação básica e em saúde de mulheres Kalunga, é necessário, contextualizá-la enquanto resultado das formas de organização social e de produção, as quais podem gerar grandes desigualdades nos níveis de vida. O contexto de vulnerabilidade desses povos corrobora o proposto, uma vez que o processo saúde-doença é eminentemente social, influenciado pelas relações dos homens com a natureza (meio ambiente, espaço, território) e com outros homens (por meio do trabalho e das relações sociais, culturais e políticas), em um determinado espaço geográfico e tempo histórico. ${ }^{24}$

\section{CONCLUSÃO}

No presente estudo, verificou-se que nas diferentes abordagens dadas pelos trabalhos analisados, que as comunidades remanescentes dos quilombolas têm empreendido lutas pelos direitos à educação, saúde, cidadania, igualdade e territoriali- 
dade, no conjunto das reivindicações pela posse da terra, pelos bens considerados sagrados e formadores de uma identidade étnica, pois são detentores de um patrimônio cultural rico e valoroso, porém, desconhecido de muitos, cuja identidade étnica constitui a base de suas vivências cotidianas.

Compreende-se que se faz necessário aprofundar os estudos nessa população, pois as discussões acerca de um processo de empoderamento das mulheres Kalunga, remanescentes dos quilombolas, muitas vezes reverberam como utópicas, o que em grande parte motivou essa pesquisa, pois o próprio método do materialismo histórico dialético fornece ferramentas para olhar a história, buscando apreender o significado da atividade emancipatória.

Por fim, os objetivos dessa revisão siste- mática foram atingidos sugerindo lacunas em torno das questóes raciais e a materialização das conquistas na prática, mostrando algumas contradições envolvidas no processo de construção da identidade quilombola, na educação, saúde e no autoconhecimento apontando a resistência quilombola na luta por seus direitos à escolarização, a saúde, à sobrevivência e a um futuro melhor.

\section{REFERÊNCIAS}

1. Ribeiro GA. Produtividade agrícola e mudanças socioculturais: a agricultura quilombola no Vale do Ribeira-SP Brasil. Revista Desenvolvimento e Meio Ambiente. 2016; 16(2): 1653-1666.

2. Alves ICS. Políticas Públicas, Territorialidade e Liberdade dos Remanescentes de Quilombo Kalunga no Nordeste Goiano. Revista UNB. 2015; 23(4): 86-95.

3. Pereira EN. A prática educativa e as contribuiç̧ões do processo formativo da organicidade da licenciatura em educação do campo da UnB - um estudo de caso no território Kalunga/Goiás. Revista Universidade de Brasília. 2013; 12(2): 178-186.

4. Silva MJ. Kalunga entre a tradição e a modernidade: experiências vivenciais com o processo de modernização de comunidades negras do sítio histórico 'Kalunga', no norte de Goiás. Revista FAFICH/UFMG. 2014; 42(1): 184-195.

5. Lima LNM. Quilombos e políticas de reconhecimento: o caso do Campinho da Independência. Revista da Universidade de São Paulo. 2013; 34(2): 178-191.

6. Camerini K. Origem e histórico do quilombo na África. Revista Universidade de São Paulo-USP. 2015; (28); 56-63.

7. Souza FGCM; Prioste F. Quilombos no Brasil e direitos socioambientais na América Latina. Revista Direito e Práxis. 2017; 18(4): 2903-2926.

8. Marinho TA. Políticas públicas e quilombolas: questões para debate e desafios à prática extensionista. Revista Extensão Rural. 2016; 16(4): 67-83.

9. Gomes L. Uso e diversidade de plantas medicinais em uma comunidade quilombola no Raso da Catarina, Bahia. Revista Acta Botânica Brasílica. 2018; 26(4): 796-809.

10. Galvão TF; Pansani TDSA; Harrad D. Principais itens para relatar Revisões sistemáticas e Meta-análises: A recomendação PRISMA. Revista Epidemiologia e Serviços de Saúde. 2015; 24(2): 335-342.

11. Carril LFB. Os desafios da educação quilombola no Brasil: o território como contexto e texto. Revista Brasileira de Educação. 2017; Jun 2017; 69 (1): 539-564.

12. Pedroza CBA; Furtado MB. Educação quilombola e formação docente. Revista Reamec. 2016; 1(10): 77-100.

13. Araújo SER; Foschieira AA. As contradições entre a realidade socioeconômica da comunidade quilombola mimoso do kalunga e a garantia dos direitos legais de educação e território. Revista de Pedagogia-USP. 2018; 48(1): 998-1007.

14. Lima LNM. A constituição de um território identitário pela garantia dos direitos fundiários: o sítio histórico e patrimônio cultural kalunga. Revista Sociedade e Natureza. 2015; 25 (3): 503-512.

15. Custódio ES; Foster ELS. Educação Escolar Quilombola no Brasil: uma análise sobre os materiais didáticos produzidos pelos sistemas estaduais de Ensino. Revista Educação. 2019; 12(1): 101-109.

16. Franco LLSG. Educação quilombola, resistência e empoderamento: estudo na comunidade quilombola de são domingos, em Paracatu. Revista Interdisciplinar da Universidade Federal de Uberlândia. 2018; 5(2):53-66.

17. Cardoso LFC. Utilização de serviços de saúde por população quilombola do Sudoeste da Bahia, Brasil. Cadernos de Saúde Pública. 2016; 29 (2): 1829-1842.

18. Camerini JCB. Os quilombos perante o STF: a emergência de uma jurisprudência dos direitos étnicos. Revista de Direito Getúlio Vargas. 2016; 1(2): 19-35.

19. Santos C. Formação de professores: compromisso com empoderamento e autoridade. Revista Unioeste. 2016; 11(3): 100109.

20. Falkenberg MB; Mendes TDPL; Moraes EPD; Souza EMD. Educação em saúde e educação na saúde: conceitos e implicações para a saúde coletiva. Revista Ciência e Saúde Coletiva. 2014; 19(1): 847-852.

21. Real RNSV. Ser Kalunga: entre a modernidade e a tradição. Revista de História Unicamp. 2015; 14(1), 101-119.

22. Almeida MG. Território e a comunidade kalunga: quilombolas em diversos olhares. Revista da Universidade Federal de Goiás. 2015; 7(1): 266-271.

23. Castilho S; Carvalho F. Educação e quilombo: delineamento dos estudos brasileiros. Revista de Estudos em Educação. 2015; 12(3): 353-369.

24. Oliveira WJF. Autopercepção de saúde em quilombolas do norte de Minas Gerais, Brasil. Revista Ciência e Saúde Coletiva. 2015; 20(2): 2879-2890. 